\section{Buchrezension zu: Die Welt mit anderen Augen sehen}

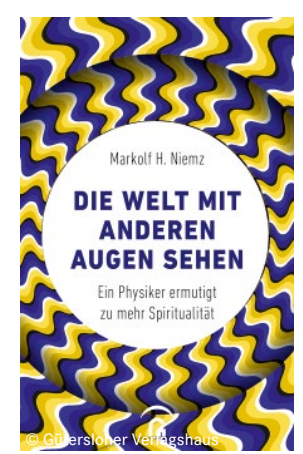

Die Welt mit anderen Augen sehen

Ein Physiker ermutigt zu mehr Spiritualität

Markholf H. Niemz

192 S., Gütersloher Verlagshaus, 2020. $H C$ mit $S U, 20,-€$.

ISBN: 9783579062129

DOI: $10.1007 / \mathrm{s} 12268-020-1495-\mathrm{y}$ (C) Springer Verlag GmbH 2020

Was sind diese „anderen Augen" des Buchtitels? Offenbar nicht die des Physikers im Allgemeinen, sonders des Autors und Experten für Laserlicht, des Physikers und Inhabers eines Lehrstuhls für Medizintechnik der Universität Heidelberg, des sensiblen, sympathischen Markholf Niemz, der glauben möchte, was auf der Welt unverständlich ist, der seinen (christlichen) Glauben nicht aus der Realität seines Fachwissens, sondern aus der diffusen Irrealität der Esoterik ableitet.

Der philosophische Dualismus, die Zweiteilung unserer Welt in Materie und Geist, verlor im vorigen Jahrhundert mit dem Aufblühen der exakten Naturwissenschaften seine Basis. Esoterik der verschiedensten Couleur versucht nun, die entstandene Lücke zu füllen. Denn unser Hirn scheint zwar bestens dafür geeignet, die von unseren Sinnesorganen wahrnehmbare, für unser Leben auf dieser Erde relevante Welt zu erfassen. Darüber hinaus aber versagt es kläglich, wenn es z. B. um Begriffe wie Unendlichkeit, Entstehung von Materie, Leben, Be- wusstsein, Willensfreiheit geht. Esoterik, im Buchtitel ,Spiritualität' genannt, bedeutet Freiheit von den schwer verständlichen Gesetzen der Natur. Alles ist möglich, wenn man z. B. aus den ,Nahtoderfahrungen“ einiger Weniger einen Einblick in ein Jenseits ableitet; wenn man wie Niemz aus der Naturkonstante , $c^{\prime}$ die Existenz eines ubiquitären Paradieses des Lichts folgert. (Der Autor dieser Rezension wurde drei Mal nach Herzstillstand reanimiert und erlebte nichts dergleichen.)

Niemz geht von Einsteins Relativitätstheorie aus. Er eröffnet seinen Weg zur Esoterik mit einer anschaulichen Beschreibung der Raum/Zeit. Durchaus im Einklang mit der Wissenschaft fasst er zusammen: „Es gibt keinen Raum ohne Zeit und keine Zeit ohne Raum. Raum und Zeit sind zwei Seiten einer Medaille“. Auch dem zweiten Kapitel - Niemz nennt seine Kapitel ,Challenge', Herausforderung - kann der Wissenschaftler zumindest in Teilen zustimmen. Er schildert hier die üblichen Gedankenexperimente und Konsequenzen der Relativitätstheorie. Und er stellt die besondere Rolle des Lichts für den Kosmos dar: „Ewigkeit ist das Sein im Licht“; „Etwas ist ewig, wenn es stets im Licht abrufbar ist“. Zumindest Formulierungen dieser Art klingen esoterisch. Ob die theoretische Physik der Relativität sie wenigstens im Ansatz hergibt, ist für den Laien nicht zu beurteilen. Der Schlussfolgerung dieser zweiten ,Challenge' möchte man zustimmen: „Sein und Werden sind nicht zwei. Sein und Werden sind zwei Seiten einer Medaille. Die Medaille heißt Kosmos". Und so erübrigt sich die Frage, wer war zuerst, das Huhn oder das Ei? Der Schöpfer oder die Schöpfung? Gut oder Böse? Verständnis oder Liebe? Alles hängt mit allem zusammen, alle Antworten ergeben sich aus dem Bild eines einheitlichen, umfassenden, ewigen Kosmos. Und aus der Relativitätstheorie. Das Abgleiten auf der slippery slope von der harten (bewiesenen) Theorie zum esoterischen Gesäusel ist schwer zu stoppen, die Grenze zwischen ernsthafter Wissenschaft und unbewiesenem Wunschdenken ist schwer zu ziehen.

Eine vertane Chance, schade: Die Physik unserer Zeit hat seit Einstein den Mut, über unsere begrenzte Anschauung hinaus zu denken, die Grenzen unserer sinnlichen Wahrnehmung durch Mathematik zu erweitern. Astrophysiker blicken seit Hubbe/ mit Superteleskopen viele Milliarden Jahre zurück in die Vergangenheit des Kosmos. Sie sehen, wie Materie aus Unebenheiten einer extrem schwachen „Hintergrundstrahlung " evolviert. Und Hochenergiephysiker mit gewaltigen Teilchenbeschleunigern bestätigen, was sie dort sehen. Gemeinsam formulieren sie eine plausible, in sich schlüssige Kosmologie, die zwar zahlreiche unverstandene und noch zu erforschende Lücken enthält, jedoch keinen diskontinuierlichen Eingriff einer Schöpferpersönlichkeit. Evolution aus immateriellen Vorstufen von Atomen und Molekülen bis zur lebenden, denkenden, sich selbst bewussten Materie braucht keinen von pfiffigen Theologen antropomorph konzipierten Schöpfergott oder dessen intelligent design. Der Berliner Philosoph Volker Gerhard sieht das Göttliche im „Ganzen“, Evolution ist Schöpfung, Gott ist „das Ganze" - und wir Menschen sind dessen, wenn auch winziger Teil. Das Ganze schließt die Naturgesetze ein. Spiritualität bzw. Esoterik hat (ebenso wie ,Transzendenz') nichts damit zu tun.

Niemz' Buch möchte ich dennoch dem Leser empfehlen. Es hilft dabei, die Fakten für sich zu sortieren, sich zu positionieren. Ferdinand Hucho, Berlin,

hucho@chemie.fu-berlin.de 